\title{
Burden of Care: Management of Cleft Lip and Palate
}

\author{
Jyotsna Murthy ${ }^{1}$ \\ ${ }^{1}$ Department of Plastic Surgery, Cleft and Craniofacial Center, \\ Sri Ramachandra University, Chennai, India
}

\begin{abstract}
Address for correspondence Jyotsna Murthy, MS, MCh (Plastic), DNB, PhD, Department of Plastic Surgery, Sri Ramachandra Medical College and Research Institute, Porur, Chennai 600 116, India (e-mail: murthyjyotsna@gmail.com).
\end{abstract}

\begin{abstract}
Keywords

- cleft lip and palate

- burden of care

- NAM

- preoperative orthodontics procedures

- cleft lip revision

Burden of care has become a commonly used terminology in healthcare in the recent years. Burden of care is the balance how much patients and families commit to their time, compromise quality of life, undergo multiple interventions, and take risks weighing against the benefits the patients and families receive. Cleft lip and palate, congenital anomaly, demands a long-term and interdisciplinary care. These children are at high risk of various treatment/intervention episodes increasing the burden of care. This subject has been widely discussed with many other diseases and health conditions at national, international meetings, and World Health Organization as well. We bring out some facts and practices affecting the burden of care in cleft lip and palate.
\end{abstract}

\section{Introduction}

India has a population of 1.2 billion people (20\% of the world's population) and a high birth rate. An estimated $7.9 \%$ of total births worldwide are born with a birth defect (March of Dimes Global Report, 2006) ${ }^{1}$ and the vast majority of these occur in low-to-middle income countries. Approximate 35,000 children are born with cleft lip and palate in India every year. Burden of care is highly relevant in the management of cleft lip and palate children because it demands multiple surgeries/interventions and a long-term follow-up. Increasing number of interventions without scientific proof of long-term benefits substantially increases the burden of care. World Health Organization (WHO) Bulletin 2014 states that a substantial burden of care increases stress on patients and families and affects negatively in the patient's emotional status. $^{2}$

\section{Burden of Care}

This is a commonly used terminology at present day in medical care. This is to titrate and balance how much patient and family commit to their time, compromise of quality of life, undergo multiple interventions, and take risk weighing against the benefits the child and family receive. As responsible cleft team professionals, it is very essential that we understand burden of care. New procedures, interventions, and surgical procedures are introduced, with promises of better results in short term. Very often these procedures and interventions have not been followed long enough time to weigh the advantages and disadvantages. Nevertheless, it is likely that these interventions and procedures will be tried on these children, probably increasing the burden of care.

\section{Healthcare Economics Its Effects}

In India, the public health expenditure is $\sim 1.3 \%$ of gross domestic product (GDP) from 2008 to 2015 without any augmentation from center or state government. In 2016 to 2017, it has marginally increased to $1.4 \%$ of GDP. It has been proposed to increase to $2.5 \%$ GDP by 2025 , and still, it is less than the world average of $6 \%^{3}$

In India, the total health expenditure is estimated at 3.9\% of GDP, which includes government and private sectors. Only $30 \%$ of this total health expenditure is contributed by the public sector, which is low in compared with Brazil (46\%), China (56\%), Indonesia (39\%), United States (48\%), and United Kingdom (83\%). This suggests that $70 \%$ of health expenditure is borne by the individual consumer. Individual consumer pays $95 \%$ of times from out of pocket and $5 \%$ of times covered by the insurance or other health schemes. Malnutrition, preventive measures, and infective/chronic diseases are the focus of the Government of India and not congenital deformities. Similarly, insurances tend to cover in-patient expenditure for acute and chronic diseases but not visible congenital defect, which is cleft lip and palate. This will clearly define
DOI https://doi.org/

10.1055/s-0039-3402353 ISSN 0970-0358.
License terms

(요 (1) $\odot$ 
that the treatment for cleft lip and palate will be often outof-pocket expenditure from parents.

Literature mentioned about "medical poverty trap" that means high out-of-pocket expenses on illness of a patient can destroy the financial stability of family and rushing them in poverty. The recovery from this economic burden is challenging for the families. Approximately 100 million people around the world are poor due to healthcare costs as per WHO estimate. It also mentioned another 150 million suffer due to catastrophic expenditure on health. In India, many publications and studies have stated that families have been pushed into poverty due to out-of-pocket expenses on healthcare. A household confronted with an illness is obliged to meet varied expenses-the cost of treatment and transport, opportunity costs for the sufferer, and caregivers and the cost of caring, besides other routine household expenses. The process of meeting these costs can impact household consumption expenditure and the standard of living. Households may simultaneously adopt coping strategies such as borrowing money at high interests, cutting back on food consumption, and sale of assets, which potentially push them into a cascading cycle of poverty. ${ }^{4}$

Recently government has come out with program (Pradhan Mantri Jan Arogya Yojana) supporting healthcare; however, eligibility is for people below poverty line and not lower middle or middle-income group. Many charitable organizations are supporting free treatment for cleft lip and palate children through private or governmental organization. However, majority of them support only surgical interventions. Some charitable organizations are trying to provide the comprehensive care with limited resources. ${ }^{5}$ These organization definitely reached to many by providing free surgical interventions. Often, these organization provides the funds according to number of surgical interventions. This provides temptation of unnecessary revision surgeries subjecting children to major psychological trauma. The burden of care is not only financial but also the family disruption, psychological and physical stress put on family and potential risk of complications of intervention, specially surgery. There are many studies about post-traumatic stress disorder(PTSD) in children undergoing surgical intervention at younger age that is as severe as war zone exposure, sexual abuse, or loss of family member. ${ }^{6}$ The subject of PTSD has been neglected and needs to be emphasized more when children are subjected to surgical intervention for not life-threatening conditions like revision of cleft lip and palate at the request of parents and family members!

\section{Protocol, Morbidity, and Burden of Care in the Management of Cleft}

Keeping in mind the long-term management of majority of children coming from middle or lower socioeconomic class, burden of care becomes is extremely relevant. The appropriate protocol is suggested in - Table $\mathbf{1}$.

While the total burden of disease in terms of both mortality and morbidity in birth defects including craniofacial anomalies is unknown, the services to deal with the care of children born with cleft lip and palate have been developing rapidly in recent years. The Clinical Standards Advisory Group study an audit that was performed to examine standards in the provision of cleft services across the United Kingdom (CSAG references, 2001)7 presented problems and difficulties of management of cleft. In this study, the approximate percentage of various morbidity and issues associated with management of cleft lip and palate are as follows:

Speech problems -5 to $30 \%$

Fistula -5 to $20 \%$

Poor dental arch relationship-40 to 50\%

Orthognathic surgery-25 to $40 \%$

Poor aesthetics of the nasolabial region (lip and nose) -20 to $40 \%$

Teasing in school-75\%

Psychological and psychosocial adjustment problems-20 to $40 \%$

WHO consensus reports in management of cleft lip and palate that the following factors are particularly relevant to developing countries and to India. Briefly summarized report included the following8:

- The burden of care throughout India has not been quantified and remains unknown.

- The disparity in healthcare systems and access to primary surgery means that there is a high unmet need in many parts of India.

- It is recognized that repair of adult clefts often requires different surgical protocols influenced not only by age of the presenting patient but also by difficulties with longitudinal care due to difficulties in achieving recall or follow-up.

- Many cleft surgeons spend too much time carrying out revisions of poorly repaired clefts of the lip and palate.

- The objectives of primary surgery in the developing world may also differ in that the unmet need requires strategies that produce functional repairs and address quantity as well as quality.

A report also highlighted an important message from the developed world to clinicians and surgeons in the developing world that "simple care can achieve equivalent or superior outcome to complex care at less human and economic cost" (Shaw et al, 1992, Severns et al, 1998).

\section{Common Causes of Burden of Care}

Donabedian ${ }^{9}$ stated that patient satisfaction should be the "ultimate validator of the quality of care." There are recognized difficulties in assessing satisfaction with respect to definitions, measurements (reliability and validity), ceiling effects, and cultural differences. ${ }^{10}$ With over more than two centuries when management of cleft lip and palate has been evolving, many scientific studies and experience of experts have put the following procedures/interventions increasing the burden of care.

\section{NAM and Preoperative Orthopaedics}

There are many articles written, mainly about technique and short-term outcome. Taiwan group, which followed 
Table 1 Protocol of essential interventions and other additional interventions increasing the burden of care

\begin{tabular}{|c|c|c|c|}
\hline & \multirow[t]{2}{*}{ Protocol intervention } & \multirow[b]{2}{*}{ Unnecessary interventions } & \multirow[b]{2}{*}{ Burden } \\
\hline & & & \\
\hline $\begin{array}{l}\text { After birth } \\
(0-3 \mathrm{mo})\end{array}$ & Feeding advice & Feeding plates, NAM, PSOP & $\begin{array}{l}\text { Multiple visits (12-20) loss of work days } \\
\text { complication }\end{array}$ \\
\hline $3-5 \mathrm{mo}$ & Cleft lip surgery & & \\
\hline Till palate surgery & No regular follow-up only on demand & $\begin{array}{l}\text { Frequent follow-up to review } \\
\text { scars }\end{array}$ & Travel cost, loss of work \\
\hline $10-12$ mo & $\begin{array}{l}\text { Cleft palate surgery } \\
\text { Council for speech and dental care }\end{array}$ & & \\
\hline $2-5 y$ & $\begin{array}{l}\text { Yearly follow-up for speech and dental } \\
\text { checkup and home program (institu- } \\
\text { tional intervention when necessary) }\end{array}$ & $\begin{array}{l}\text { Institutional speech therapy } \\
\text { and dental checkup (institu- } \\
\text { tional-based therapy) }\end{array}$ & $\begin{array}{l}\text { Travel cost, loss of work days, and school } \\
\text { days }\end{array}$ \\
\hline $3-4 y$ & $\begin{array}{l}\text { Surgery for functional fistula, and } \\
\text { preferably to combine with VPI } \\
\text { surgery }\end{array}$ & $\begin{array}{l}\text {-Preschool rhinoplasty } \\
\text {-Minor lip correction } \\
\text {-Nonfunctional fistula repair }\end{array}$ & $\begin{array}{l}\text {-Psychological trauma to children } \\
\text {-Cost } \\
\text {-More scaring } \\
\text {-Risk of anesthesia }\end{array}$ \\
\hline $5-7 y$ & $\begin{array}{l}\text { VPI evaluation and management } \\
\text { (often fistula repaired combined)+ } \\
\text { speech therapy }\end{array}$ & & \\
\hline $7-9 y$ & $\begin{array}{l}\text { No orthodontics, except to prepare } \\
\text { for ABG }\end{array}$ & $\begin{array}{l}\text { Mixed dentition orthodontics } \\
\text { intervention }\end{array}$ & $\begin{array}{l}\text { Poor oral hygiene } \\
\text { More dental issues demand long main- } \\
\text { tenance }\end{array}$ \\
\hline $9-10 y$ & Alveolar bone graft & & \\
\hline $10-15 y$ & $\begin{array}{l}\text { Revision lip nose correction on de- } \\
\text { mand by patients }\end{array}$ & $\begin{array}{l}\text {-Multiple cleft lip nose } \\
\text { revisions } \\
\text {-Orthodontic } \\
\text {-Surgical intervention like } \\
\text { AMD to correct class III }\end{array}$ & $\begin{array}{l}\text {-Cost } \\
\text {-Risk of anesthesia } \\
\text {-High relapse }\end{array}$ \\
\hline $15-19 y$ & $\begin{array}{l}\text { Correction of Class III occlusion } \\
\text { Orthodontic Treatment } \\
\text { Rhinoplasty on demand of patients }\end{array}$ & & \\
\hline
\end{tabular}

Abbreviations: AMD, anterior maxillar distraction; NAM, naso-alveolar molding; PSOP, pre-surgical orthognathic procedures; VPI, velo-pharyngeal incomptence.

up for long term, did not show significant improvement in nasolabial appearance in a long term. Dutch study, which conducted randomized controlled trial on preoperative plate molding, did not show any improvement in feeding, aesthetic outcome, speech, and growth outcome. ${ }^{11}$ In addition, often, the complication of nasoalveolar molding (NAM) that a newborn baby faces ranges as high as 25 to $40 \%$, which are though minor, never presented with outcome results. ${ }^{12}$ Too much aggressive forces on arches lead to permanent bending of vomer that has never been followed up to know longterm consequences. ${ }^{13}$ On personal communication, with Prof. David Huang (Taiwan) mentioned that role of NAM is to support surgeon if they are not capable of handling wide cleft. This fundamentally suggested that improvement in skills and knowledge of surgeon would reduce major burden of care of preoperative orthopaedic.

\section{Multiple Cleft Lip Nose Revisions}

Cleft lip nose revision surgery is commonly performed when results of primary surgeries do not produce aesthetically acceptable results. ${ }^{14}$ Any surgical intervention is a major event for patients and families. Cleft lip nose revision puts financial burden on families and increases burden of care. ${ }^{15-17}$ This includes cost of surgical procedure and indirect cost of travel and lost productivity for patients and their families. Furthermore, cleft lip nose revision does not improve aesthetic outcome in all patients all the times. And, it can even become worse than before. ${ }^{18}$ Meta-analysis of 45 studies out of 3,034 in 2016 on cleft lip revision surgeries in unilateral cleft lip has eye-opening observation. This study outcome shows that the revision surgery ranges from 0 to $100 \%$ in different centers with extremely variable outcomes! $1^{9}$ Quality of primary cleft lip nose repair with specific treatment protocol and threshold of surgeon to do revision surgery contributes to a great extent to this wide variation in incidence of revision surgeries. ${ }^{7}$ Access to healthcare and insurance status, socioeconomic status, and health literacy largely increases incidence of revision of surgeries. Furthermore, eagerness of surgeon to do revision surgery and readiness of patient and family to undergo more surgeries also plays a significant role. ${ }^{18-21}$ It is obvious that more studies are necessary to understand the variation in number of revision surgeries and its benefits against burden of care. It is well known fact that improving outcome of primary cleft lip repair will reduce the number of secondary revision surgeries.

The Americleft Project ${ }^{21}$ shows that cleft revision surgery may have improved the aesthetic outcome for individual 
patient, but in a group of patients, children with added revision surgery did not have better aesthetic outcome than those had only primary surgeries. This outcome shows that final result of revision surgeries is highly variable across different center. And, therefore, revision surgery does not improve aesthetic outcome in all children and definitely increase the burden of care.

In India, there are many special compulsions and socioeconomic issues that increase the numbers of cleft lip nose revision, for example, economical incentives, demands from institutions and organizations of increasing number of interventions, uninformed patients/parents, and professional falling short of the ethical practices.

\section{Burden of Speech Care}

There are nearly no scientific studies to know the burden of care in speech management. There are too many variables, and literature is full of different types of interventions and outcome studies without long-term outcome and burden of care. We need to understand the effectiveness of speech therapy, especially institutional based and its limitation. We need to respect the patients'/parents' opinion, their compensation, and their social milieu rather than enforcing the Western type of institutional based speech therapy on our patients. Our institutional based work on community-based speech therapy has made us humble to know how much parents struggle to bring the child for one session of therapy of 30 minutes by traveling $250 \mathrm{~km}$, changing 3 busses, and walking $10 \mathrm{~km}$ to reach the bus. In addition, we often make parents guilty of not doing enough for their children, forcing them to disturb family mechanics, and compromising the family nutrition, income, and stress. Professional needs to take holistic view of patients, family, and society and provide the best possible without disturbing the dynamics of their social life.

\section{Burden of Orthodontic Treatment}

There are too many variables and too many views regarding additional procedures such as NAM, mixed dentition orthodontics, mix dentition orthognathic surgeries such as anterior maxillar distraction (AMD) and other intervention. Often, we see children under orthodontic care from 8 to 14 years, which is prime and critical time of their life.

Eurocleft Study ${ }^{22}$ is a well-planned long-term outcome study from European centers where all the resources and supports are available for the cleft children. Eurocleft Study showed that two centers who had lowest ranking for eventual outcome had highest number of interventions of early treatment including hospitalization for presurgical orthopaedics. Other centers having the longest orthodontic interventions and high number of orthodontic visits showed less favorable outcome. These centers had complex orthodontic protocol and close follow-up from early childhood till adulthood. These experiences showed that there is no association between treatment outcome and intensity. And, therefore, simple protocol with minimum economic burden can provide better or equally good outcome with less burden of care.
Another astonishing finding of Eurocleft Study was that there is inconsistency between objectively rated outcome and satisfaction of patient and family. Though center may have good rating of objective outcome, and this outcome is also associated with the highest dissatisfaction expressed by the subject. This demands the need to develop individual protocols that are patient centric and more holistic model of cleft care. $^{23}$

The best way to understand them is from the comments of pioneers who have given their lifelong commitment to this field.

- Maria Mazzini24: In her study she presented that children showing early skeletal discrepancy in childhood were more likely to have final jaw surgeries. At age of 5 years, the outcome of ANB angle identified $45 \%$ of the need for orthognathic surgery. Early or prolong orthodontic treatment did not change growth pattern or final outcome of craniofacial pattern.

- Gunvor Semb ${ }^{23}$ : In her protocol, no presurgical or primary dentition treatment was done. Some received a short period of orthodontic treatment just before alveolar bone graft (ABG) to facilitate the operation. Definitive orthodontics performed in the permanent dentition. Patients who choose to have orthognathic surgery needed a third period of orthodontics in conjunction with this operation. Independent analysis of a 40 -year archive of consecutive patients with complete clefts from birth to age 21 confirmed the protocol to be acceptable. The total mean duration of orthodontic treatment was 2.9 years for unilateral cleft lip and palate (UCLP) and 3.3 years for bilateral cleft lip and palate (BCLP). This was not very different from the duration of treatment in complex noncleft individuals. At 21 , the occlusion was good in $~ 70 \%$ and fair in $17 \%$; the ABG was good in $97 \%$, and in $90 \%$, orthodontic space closure without prostheses was possible. Since 1960s the guiding principle for orthodontic cleft care in Oslo (set down by Olav Bergland) was to minimize burden of care.

\section{Compulsions Augmenting Burden of Care}

\section{(Difficult to Accept, but Unconsciously Work)}

- New techniques presented with short-term benefits added without scientifically studies of long-term benefits and consequences and burden of care.

- Demand to produce more publications: Series of specific procedure and intervention in specific number of patients is done to bring out publications.

- Attraction of more incentive for professionals for providing more care.

- Medical Council of India (MCI) compulsion of more admissions, surgeries, and interventions.

- Nongovernmental organizations supported surgeries are easily done than avoided and often encourage secondary surgeries.

- Not giving information on alternatives, risks, hardship, and long-term benefits and lack of evidences to patients and parents. 
- Minimal awareness among the patients about the available options, consequences of intervention, and associated risks has galvanized today's practice in doing far more interventions than necessary.

- Surgeon's enthusiasm: With simple statement like "want the best for my patients" or "want my patient to look normal" increases interventions that never take out cleft stigmas. These professionals often refuse to hear the real issues of patients' willingness and fail to organize patient-centric treatment.

..... All above factors do not motivate a surgeon to improve quality outcome of primary surgeries, which will reduce many of these interventions. It is time that system is introduced to evaluate the outcome or primary surgery and economical incentive are planned accordingly!!!!!!! This will be revolutionary!!!!

\section{How Can Cleft Team Reduce the Burden of Care?}

Many cleft centers in India achieve excellent results with much less morbidity than the figures quoted above, but there is a great deal of variability in quality of care. How these problems could be addressed? The foremost is we start understanding and talking about the burden of care in scientific meetings and literature. ${ }^{23}$

- Creation of "centers of excellence": The rehabilitation of patients with cleft lip and palate in the best centers in the world has shown that tremendous benefits and the best outcome can be achieved.

- Analyzing the outcome results: Studying own outcome, comparing with national and international studies, and improvise for the better outcome.

- Intercenter studies: Intercenter studies will help to improve and learn from each other

- Protocols: Protocols with minimum interventions and adherence to the guidelines.

- Expertise of team members: Improve individual skills knowledge and commitment of team members to their patients. Augment the expertise of whole team, as team is as strong as the weakest member of the team

- Patient-centric treatment: Learn and look in to child psychology and listen to them. If not able to make judgment on child psychological issue, please get help from child psychologist.

\section{Funding}

None.

\section{Disclaimers}

None.

\section{Conflict of Interest}

None.

\section{References}

1 Global Report on Birth Defects, The Hidden Toll of Dying and Disabled Children: March of Dimes Birth Defect Foundation, 2006, https://www.marchofdimes.org/global-report-on-birthdefects-the-hidden-toll-of-dying-and-disabled-children-fullreport.pdf

2 The effectiveness of interventions to reduce household economic burden of illness and injury: a systemic review. Bull World Health Organ 2014;93(2):102-112B

3 Healthcare Financing: Who is Paying? Nivdita Rao, April 280, published on PRS Legislative Research. Blog on www.prsindia.org

4 Bajpai V, Singh N, Sardana H, Kumari S, Vettiyil B, Saraya A. Economic and social impact of out-of-pocket expenditure on households of patients attending public hospitals. Natl Med J India 2017;30(1):15-20

5 Upadhyaya DN. Cleft care in India: current scenario and future directions. J Cleft Lip Palate Craniofacial Anomalies 2018;5(2):61-62

6 Ari AB, Peri T, Margalit D, Galili-Weisstub E, Udassin R, Benarroch $F$. Surgical procedures and pediatric medical traumatic stress (PMTS) syndrome: assessment and future directions. J Pediatr Surg 2018;53(8):1526-1531

7 Semb G, Brattström V, Mølsted K, et al. The Eurocleft study: intercenter study of treatment outcome in patients with complete cleft lip and palate. Part 4: relationship among treatment outcome, patient/parent satisfaction, and the burden of care. Cleft Palate Craniofac J 2005;42(1):83-92

8 Shaw W. Global Strategies to Reduce the Health Care Burden of Craniofacial Anomalies: Report of WHO Meetings on International Collaborative Research on Craniofacial Anomalies. 2000, bookorder@who.int

9 Donabedian A. Evaluating the quality of medical care. Milbank Mem Fund Q 1966;44(3):166-206

10 Bowling A. Research Methods in Health: Investigating Health and Health Services. Buckingham: Open University Press; 1997

11 Severens JL, Prahl C, Kuijpers-Jagtman AM, Prahl-Andersen B. Short-term cost-effectiveness analysis of presurgical orthopedic treatment in children with complete unilateral cleft lip and palate. Cleft Palate Craniofac J 1998;35(3):222-226

12 Levy-Bercowski D, Abreu A, DeLeon E, et al. Complications and solutions in presurgical nasoalveolar molding therapy. Cleft Palate Craniofac J 2009;46(5):521-528

13 Mishima K, Sugahara T, Mori Y, Minami K, Sakuda M. Effects of presurgical orthopedic treatment in infants with complete bilateral cleft lip and palate. Cleft Palate Craniofac J 1998;35(3):227-232

14 Stal S, Hollier L. Correction of secondary cleft lip deformities. Plast Reconstr Surg 2002;109(5):1672-1681, quiz 1682

15 Abbott MM, Meara JG. A microcosting approach for isolated, unilateral cleft lip care in the first year of life. Plast Reconstr Surg 2011;127(1):333-339

16 Abbott MM, Meara JG. Value-based cleft lip-cleft palate care: a progress report. Plast Reconstr Surg 2010;126(3):1020-1025

17 Trotman CA, Phillips C, Essick GK, et al. Functional outcomes of cleft lip surgery. Part I: Study design and surgeon ratings of lip disability and need for lip revision. Cleft Palate Craniofac J 2007;44(6):598-606

18 Trotman CA, Faraway JJ, Phillips C, van Aalst J. Effects of lip revision surgery in cleft lip/palate patients. J Dent Res 2010;89(7):728-732

19 Sitzman TJ, Coyne SM, Britto MT. The burden of care for children with unilateral cleft lip: a systematic review of revision surgery. Cleft Palate Craniofac J 2016;53(4):84-94 
20 Cassell CH, Meyer R, Daniels J. Health care expenditures among Medicaid enrolled children with and without orofacial clefts in North Carolina, 1995-2002. Birth Defects Res A Clin Mol Teratol 2008;82(11):785-794

21 Cassell CH, Meyer RE, Farel AM. Predictors of referral to the North Carolina Child Service Coordination Program among infants with orofacial clefts. Cleft Palate Craniofac J 2007;44(1):45-51

22 Sallis JF, Owen N, Fisher EB. Ecological models of health behavior. In: K Glanz, Rimer BK, Viswanath K, eds. Health Behavior and Health Education: Theory, Research, and Practice CA, San Francisco: Jossey-Bass; 2008:465-495

23 Sitzman TJ, Mara CA, Long RE, Jr, et al. The Americleft Project: burden of care from secondary surgery. Plast Reconstr Surg Glob Open 2015;3(7):e442
24 Shaw WC, Brattstrom V, Molsted K, Prahl-Andersen B, Roberts CT, Semb G. The Eurocleft study: intercenter study of treatment systematic review of unilateral cleft lip revision surgery outcome in patients with complete cleft lip and palate. Part 5: discussion and conclusions. Cleft Palate Craniofac J 2005;42:93-98

25 Semb G, Rønning E, Åbyholm F. Twenty-year follow-up of 50 consecutive patients born with unilateral complete cleft lip and palate treated by the Oslo cleft team, Norway. Semin Orthod 2011;17(3):207-224

26 Meazzini MC, Capello AV, Ventrini F, et al. Long term follow up of UCLP patients: surgical and orthodontic burden of care during growth and final orthognathic surgery. Cleft Palate Craniofac J 2015;52(6):688-697 